\title{
A New Type of High Power Vacuum Tube
}

\author{
By W. WILSON
}

SyNopsis: The type of vacuum tube described in the present article is likely to become one of the most remarkable devices of modern electrical science. Vacuum tubes capable of handling small amounts of power have been extensively used during the past few years as telephone repeaters and as oscillators, modulators, detectors and amplifiers in radio transmission and other fields. Practically all such tuhes have depended upon thermal radiation from the plates to dissipate the electrical energy which the device necessarily alisorbs during its operation. With present methods of construction, and using glass for the containing tulb, a fairly definite upper limit can be set for the power which a radiation coaled tulse can handle: is the author foints out, this limit gives a tube capable of clelivering alout $\mathrm{i}$ to $2 \mathrm{k}$. w. when used as an oscillator.

Contrasted with this, one of the water-cooled vacuum tubes described herewith, although scarcely two feet in length and weighing only ten pounds, is capable of delivering $100 \mathrm{k}$. w. of high frequency energy. Another tube of similar construction, but somewhat smatler in size, and capable of delivering about $10 \mathrm{k}$. $w$. is also described. It is expected that these watercoolerl tuhes will find important applications in radio telephony and tolegraphy:

Athough the grinciple of operation of the water-cooled tube describerd in this article is identical from an electrical point of view with that of the small tu!es which are now so very familiar, their practicability has only heen made possible by a new and striking development in the art of sealing metral to glass. In the case of the $100 \mathrm{k}$. $w$. tube the seal between the r.lindrical copper anode and glass portion is 3.5 inches in diameter.

The remarkable character of these copper-in-glass seals is evidenced by the fact that they do not depend upon a substantial equality between the coefficient of expansion of the metal and glass. To Mr. W. G. Houskeeper of the Bell System Research Laboratory at the Western Electric Company, goes the credit for developing the copper-in-glass seals. As the article brings out, Mr. Houskeeper has also invented means for sealing heavy copper wire and strip through glass in such a way that the best vacua can be majntained under wide changes of temperature.-Fdilor.

$\mathrm{T}$ HE development of wireless telephony and the use of continuous wave transmission in wireless telegraphy have led to the general adoption of the vacuum tube as the generator of high frequency currents in low power installations.

The ordinary form of vacuum tube is, however, ill suited for the handling of large amounts of power, and at the large wireless stations where the plant is rated in hundreds of kilowatts either the arc or the high frequency alternator is used.

The undoubted advantages to be derived from the use of vacuum tubes, especially in the field of wireless telephony where the output power must be modulated to conform to the intricate vibration pattern of the voice, has led to a demand for tubes capable of handling amounts of power comparable with those in use at the largest stations.

That the development of such tubes was of great importance was recognized by the engineers of the Bell Telephone System in the early days of the vacuum tube art. The experiments at Arlington, 
Virginia, in which speech was first transmitted across the Atlantic to Paris and across the Pacific to Honolulu, required the use of nearly 300 of the most powerful tubes then available, each capable of handling about 25 watts, and the difficulties encountered in operating so many tubes in parallel gave added impetus to the development of high power units.

It is the object of the present paper to deal with the various steps in the development of high power tubes as carried out in the Bell System research laboratories at the Western Electric Company.

The usual type of vacuum tube consists of an evacuated glass vessel in which are enclosed three elements, the filament, the plate, and the grid. When the tube is in operation an electron current flows between the filament which is heated by an auxiliary source of power and the plate, the magnitude of this current being controlled by the grid.

The passage of the current through a thermionic tube is accompanied by the dissipation in the plate of an amount of power which is comparable to the power delivered to the output circuit and which manifests itself in the form of heat. This causes the temperature of the plate in the usual type of tube to rise until the rate of loss of heat by radiation is equal to the power dissipated. Some of the heat liberated by the plate is absorbed by the walls of the containing vessel which consequently rise in temperature. These factors, together with a consideration of the size of plate that can be conveniently suspended inside a glass bulb and the size of glass bulb that can be conveniently worked, set a limit of about 1 to $2 \mathrm{k}$. w. for the power that can be dissipated in the plate of a commercial vacuum tube of this type. The plates are generally constructed of molybdenum or some other refractory metal and the containing vessel made of hard glass.

The use of quartz as the containing vessel offers certain advantages which tend to raise the power limit somewhat and this material has been used for power tube purposes in England.

It is apparent then that in the development of vacuum tubes capable of handling large amounts of power means other than radiation must be used for removing the heat dissipated at the plate, and development of tubes along these lines was undertaken by Dr. E. R. Stoekle and Dr. O. E. Buckley.

Dr. Stoekle had already worked for some years on the problem of removing the heat dissipated at the anode of a thermionic tube by making the anode a part of the outside wall of the vessel and thus making it possible to convey the heat directly away from it by means of circulating water. This was clearly the right principle but as is obvious to those who are familiar with these devices, great difficulties 
presented themselves in the mechanical construction of large tubes in which vacuum tight joints must be made and maintained between glass and large masses of metal. The importance of the problem, however, was such that Stoekle and Buckley pushed on in the face of difficulties to the construction of tubes which could handle kilowatts where previous tubes could only handle watts.

A step in the direction of overcoming these difficulties was made by Messrs. Schwerin and Weinhart, who were working with Dr. Buckley on the problem, and who suggested that the anode might be made in the form of a tube or thimble of platinum sealed into a glass vessel and kept cool hy passing water through it.

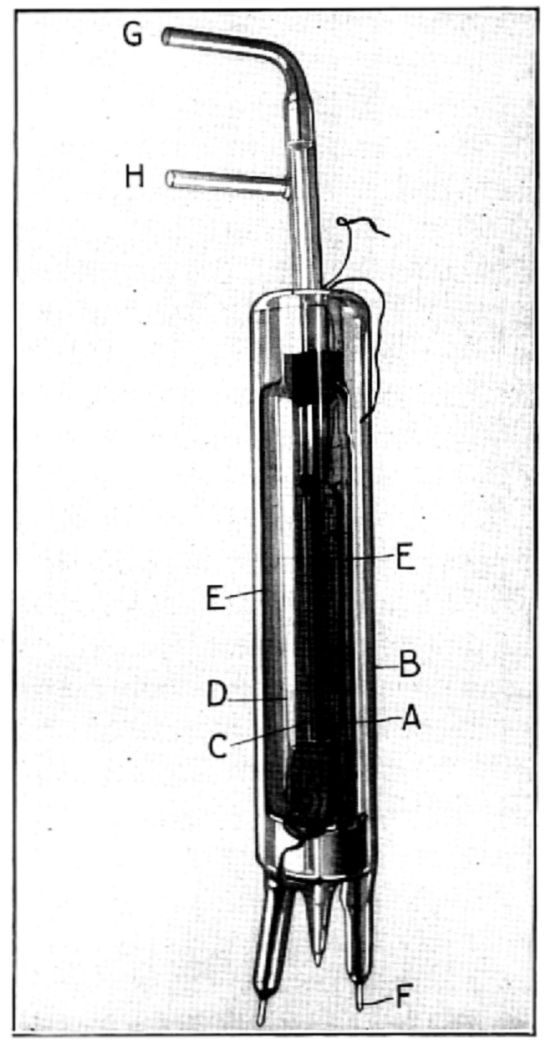

Fig. 1

This suggestion led to the development of a tube which, although not the one finally adopted, is discussed in some detail since it was the first one to be pushed to such a point as to give promise of economical commercial manufacture. 
The tube is shown in Fig. 1. The anode consists of a platinum cylinder A, $7^{\prime \prime}$ long and .625" wide, which is sealed into the center of the glass cylinder B. The end of the platinum cylinder remote from the seal is closed. The anode is surrounded by the grid $\mathrm{C}$ and by the filatment $\mathrm{D}$, which are supported by the glass arbors $\mathrm{E}$. The current for the filament is led into the tube through the platinum thimbles $F$.

The anode is kept cool by means of a supply of water passing into the anode through the tube $G$ and leaving by the tube $H$.

A number of tubes having this general type of construction were made up and it was found possible to dissipate as much as $15 \mathrm{k}$. w. in the anode.

As soon as the pressure of work more directly connected with the necessities of the war would permit, Mr. W. G. Houskeeper and Dr. M. J. Kelly undertook the further improvement of the water-cooled tube, the former assuming the task of developing the mechanical structure, and the latter that of determining the electrical design and the process of tube exhaust.

$\mathrm{Mr}$. Houskeeper adopted into the construction of the tube a remarkable type of vacuum seal which he had previously developed. These scals are made between glass and metal and can be made in any desired size. They are capable of withstanding repeated heating and cooling over wide ranges of temperature, from that of liquid air to $350^{\circ} \mathrm{C}$, without cracking and without impairment of their vacuum holding properties.

It is no exaggeration to say that the invention of these seals has made possible the construction of vacuum tubes, capable of handling in single units, powers of any magnitude which may be called for in wireless telegraph and telephone transmission.

The underlying principle connected with the making of this seal consists in obtaining an intimate connection between the glass and metal, either by chemical combination or by mere wetting, and in so proportioning the glass and metal portions of the seal that the stresses produced when the seal is heated or cooled will not be great enough to rupture either the glass or the junction between the glass and metal.

The three principal types of seals developed by Mr. Houskeeper are known as the ribhon seal, the disc seal and the tube seal.

If a copper ribbon is directly sealed through glass it is found that the glass and copper adhere along the flat faces of the seal but that ruptures occur along the edges as shown in Fig. 2 (a). This is due to the fact that as the seal cools after being made, the glass in contact with metal is capable of resisting the shearing and tensile stresses 
that occur along the faces, while the glass wrapping round the edges of the ribbon is called upon to withstand much greater tensile stresses and gives way. If the edges of the ribbon are sharpened as shown in Fig. 2 (b), a tight scal results, the reason being that the forces of
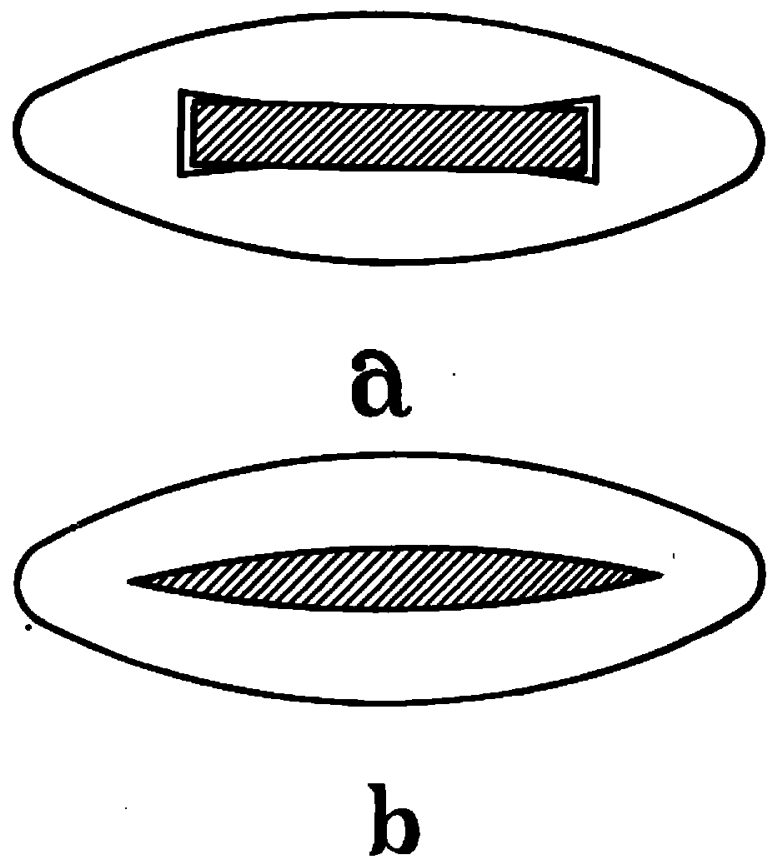

FIIG. 2

adhesion between the glass and copper acting along the flat contact faces are sufficient to stretch the thin copper at the edge and prevent its drawing away when cooled. There is a definite relation between the elastic properties of the metal and glass and the angle of edge that can be used for a successful seal.

By proper shaping of the metal ribbon, scals have been successfully made up to very large sizes. Some of these are shown in Fig. 3, the the largest in the photograph being about $1^{\prime \prime}$ in width, and capable of successfully conducting a current of 150 to 200 amperes.

The principles involved in the making of the disc seal are the same as those involved in making the ribbon seal. If a metal disc is sealed wholly into glass the edges must be sharpened or the glass and copper break away from each other as in the case of the ribbon seal.

In the general use to which these seals are put there is no necessity for having the glass surround the circumference of the copper disc 
and the necessity for sharpening the edge is obviated by allowing the glass to adhere to the flat portion of the disc only, care being taken to prevent its flowing around the edge. It is necessary to have a ring of glass on both sides of the seal in order to equalize the bending stresses

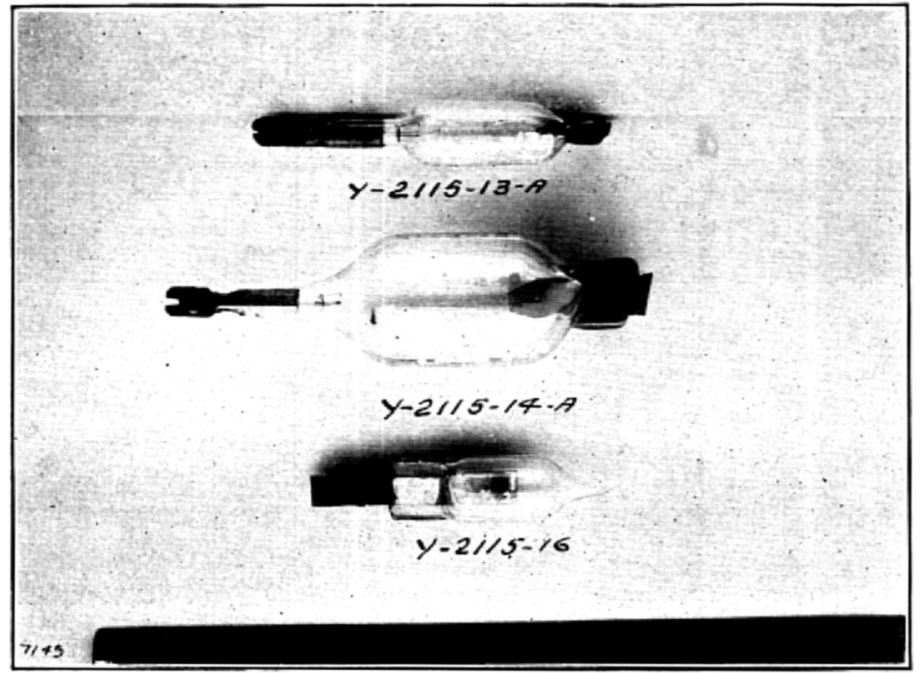

FIG. 3

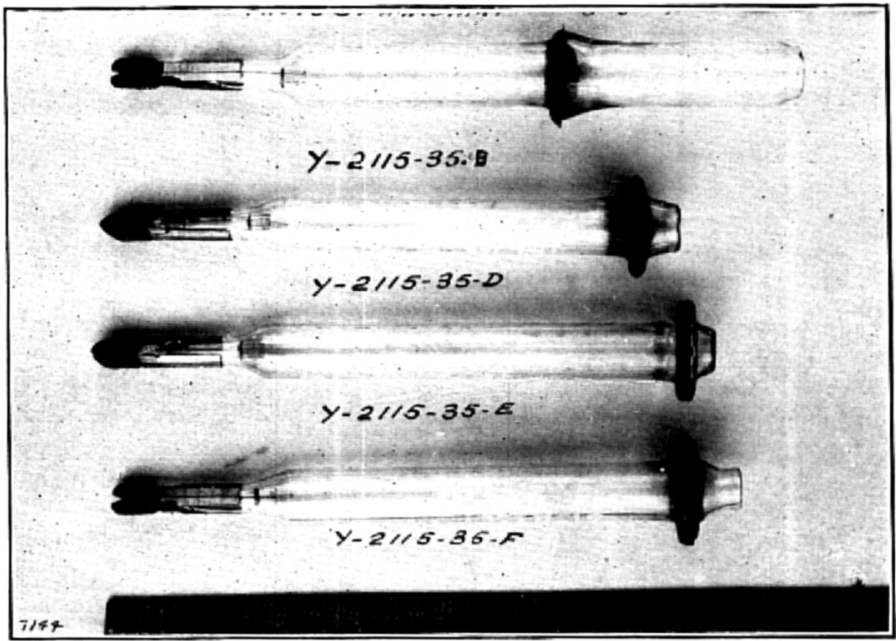

FIG. 4 
which would otherwise tend to break the glass and copper away from each other. Successful disc seals have been made with copper up to $1-10^{\prime \prime}$ thick. There is, of course, a certain maximum thickness that can be used for a seal of a given diameter and it is preferable to keep well below this limit.

The seals shown in Fig. 4 close the ends of glass tubes to the other ends of which are sealed pilot lamps for the purpose of testing the vacuum. Tubes sealed in this way have been kept a number of years without any impairment of the vacuum.
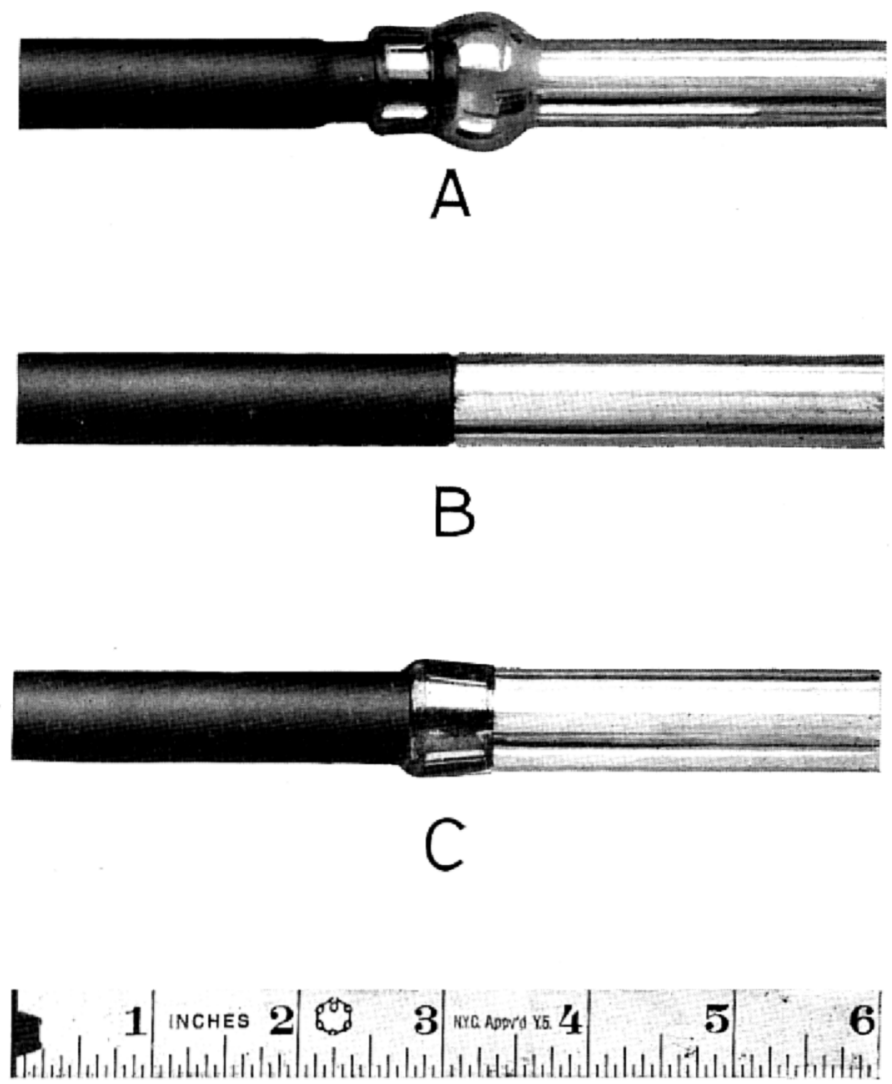

FIG. 5

The third type of seal and the most important in connection with the present problem is the tube seal shown in Fig. 5. This furnishes the means of joining metal and glass tubes end to end and is used in the water-cooled tube to attach the anode to the glass cylinder which 
serves to insulate the other tube elements. As in the case of the disc seal, it can be made either with the edge of the metal not in contact with the glass, as shown at $\mathrm{A}$, or with the metal sharpened to a fine edge which is in contact with the glass. The glass may be situated either inside or outside of the metal, see B and C.

The first thermionic tubes in which these seals were embodied were made of copper and were designed to operate at 10,000 volts and to give about $5 \mathrm{k}$. w. output.

A photograph of one of these tubes is shown in Fig. 6; and the filament grid assembly is shown in Fig. 7.

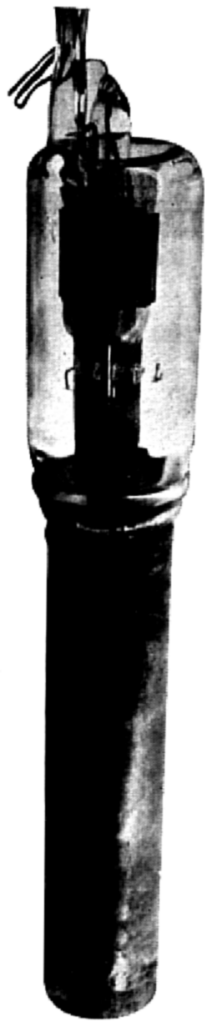

FIG. 6

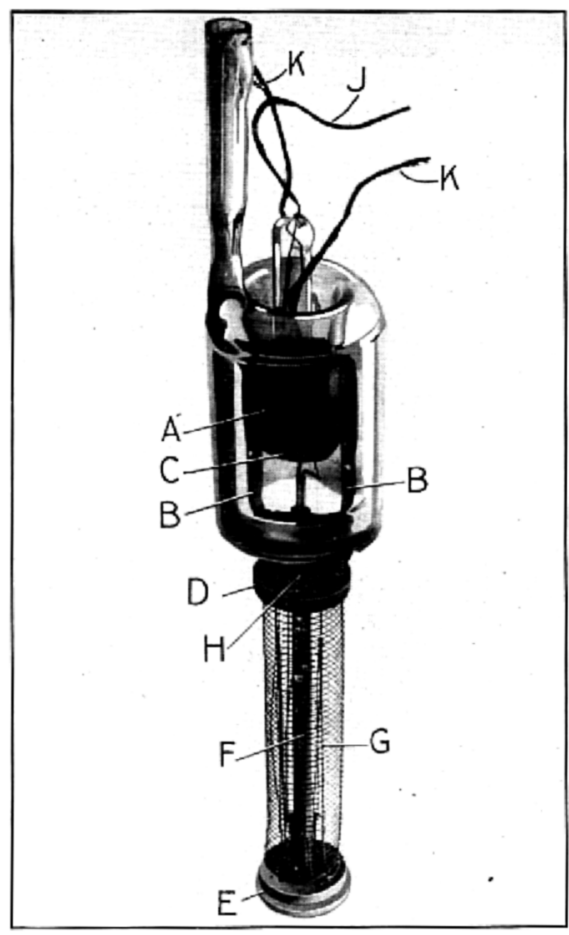

FIG. 7

The anode consists of a copper tube $1.5^{\prime \prime}$ in diameter and $7.5^{\prime \prime}$ long. A copper disc is welded to one end forming a vacuum-tight joint. The other end which is turned down to a knife edge is fused directly to a glass tube. 
The filament grid assembly consists of two lavite discs D and E, spaced $5^{\prime \prime}$ apart by a seamless steel tube. The grid $\mathrm{F}$ is made in the form of a helix, and is held in position by allowing the ends of the longitudinal wires, to which the turns of the helix are welded, to pass through holes in the lavite blocks $D$ and $E$. The filament $G$ is mounted between hooks fastened to the lavite blocks and is kept taut by the springs $H$. The grid lead is shown at $J$, and the filament leads at $\mathrm{K} \mathrm{K}$. In this tube platinum seals are used for the lead wires. The use of the springs $\mathrm{H}$ make it necessary to supply the filament with current from the opposite end of the assembly and this is done by passing the current through the steel support tube and returning it through a lead passing through this tube and insulated from it by a quartz tube.

The whole assembly is carried by two supports B B. These supports are welded to a corrugated nickel collar A which grips the glass stem C.

The pumping of these tubes at first presented considerable difficulty, chiefly on account of the large amount of occluded gas contained by the metal parts. This caused the time of pumping of the tube to be very long and a dangerous warping of the internal structure developed owing to the fact that during exhaust the tube elements are maintained at a much higher temperature than they are subjected to during normal operation. The trouble was overcome by heating the various parts of the tube to as high a temperature as possible in a vacuum furnace, prior to the final assembly, and thus getting rid of a large amount of the occluded gases. The anode was preheated before the glass seal was made and the whole filament grid assembly was preheated just before it was mounted on the glass stem. The preheating of the parts brought about an enormous reduction in the time required for pumping and gave a much more uniform product.

Although successful from the standpoint of operation, this tube had several undesirable features that it was thought well to eliminate. In the first place the welding of the end into the tube was not particularly desirable, and in general any troubles that occurred due to leaks in the metal could be traced to this point. Further, in the assembly of the tube there were a very large number of welds to be made which constituted points of weakness at the high temperature necessary for the evacuation of the tubes. It was, therefore, decided to go to a type of tube in which the anode would be drawn in one piece and in which as many welds as possible would be eliminated in the assembly of the internal elements. At the same time it was considered desirable to go to a somewhat larger type of structure in which high 
tension insulation could be more casily provided and a larger tube was, therefore, designed capable of delivering $10 \mathrm{k}$. $w$. to an antenna at a plate vol tage of 10,000 volts.

The final form adopted for this tube is shown in Figs. 8 and 9.

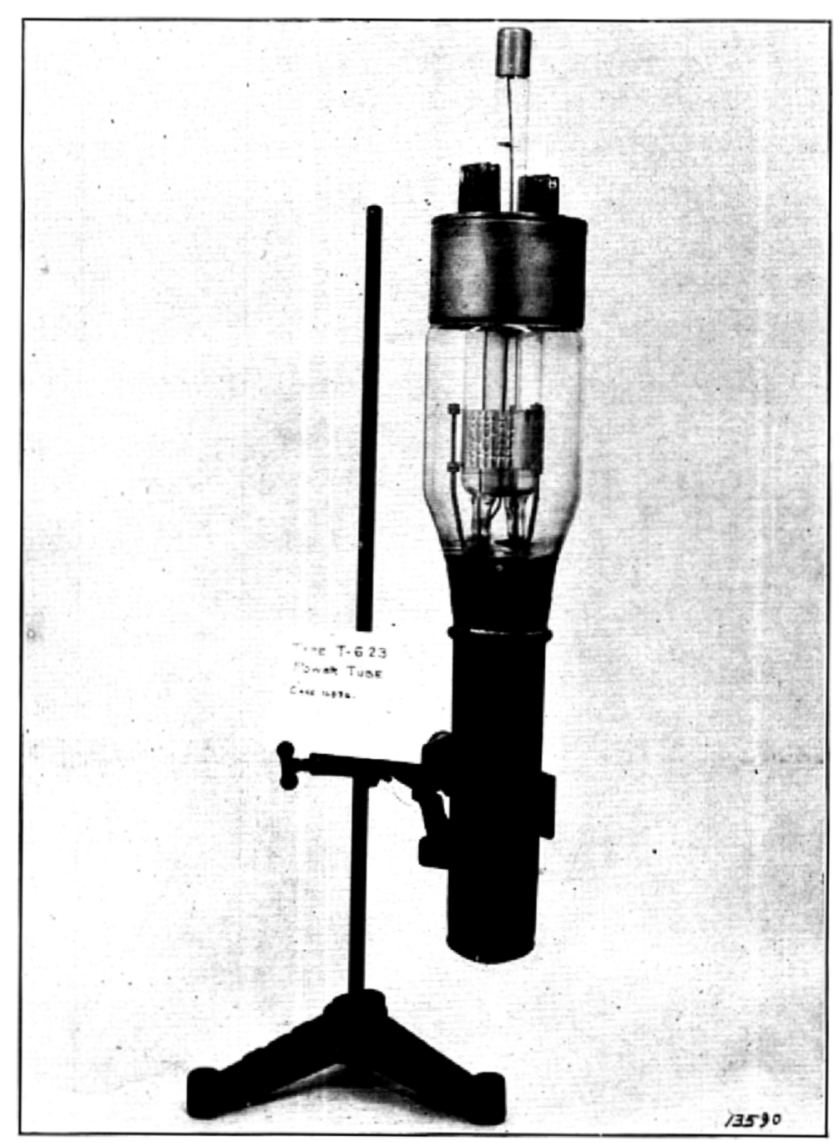

FIG. 8

The anode $A$ is drawn from a piece of sheet copper and is $9^{\prime \prime}$ long and $2^{\prime \prime}$ in diameter. The copper flare $B$ is turned down to a sharp edge and a glass bulb $\mathrm{C}$ scaled thereto. The grid and plate assembly is shown at $D$. The structure is supported by four molybdenum rods, which are threaded and secured by means of nuts to the lavite pieces $E$ and $F$. The filament is made of $19.5^{\prime \prime}$ of .025 pure tungsten wire purchased from the General Electric Company and is formed and secured to two of the molybdenum rods at $G$ and $H$. The 
power consumed in it during operation is $.75 \mathrm{k}$. w. It is guided by the hooks $J$. The filament leads are shown at $K, K$ and are led through the glass by the copper disc seals $\mathrm{L}, \mathrm{L}$. The grid is a molyb-

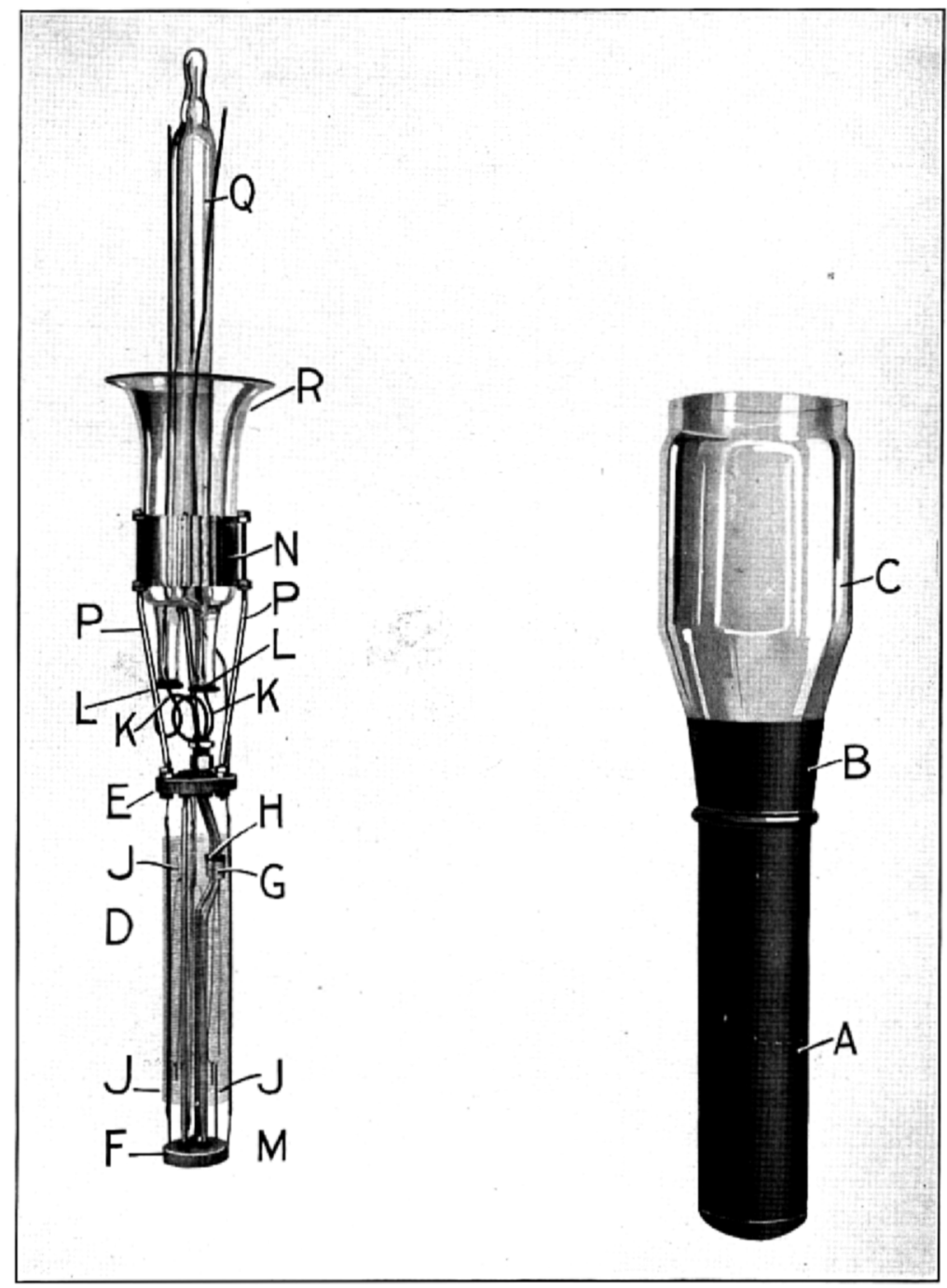

FIï. 9

denum helix and is supported by the molybdenum rods $M$ which are fixed to the lavite block $\mathrm{F}$, and slide on the outside of the lavite block F. The whole structure is mounted on the flare $R$ by means of the 
nickel collar $\mathrm{N}$ and the support rods $\mathrm{P}$. The grid lead is brought out through the tube $Q$. The tube is completed by sealing together the flare $R$ and the bulb $C$.

In this tube all welds except those in the collar $\mathrm{N}$ are eliminated, the assembly being bolted together. The drawing of the anode does

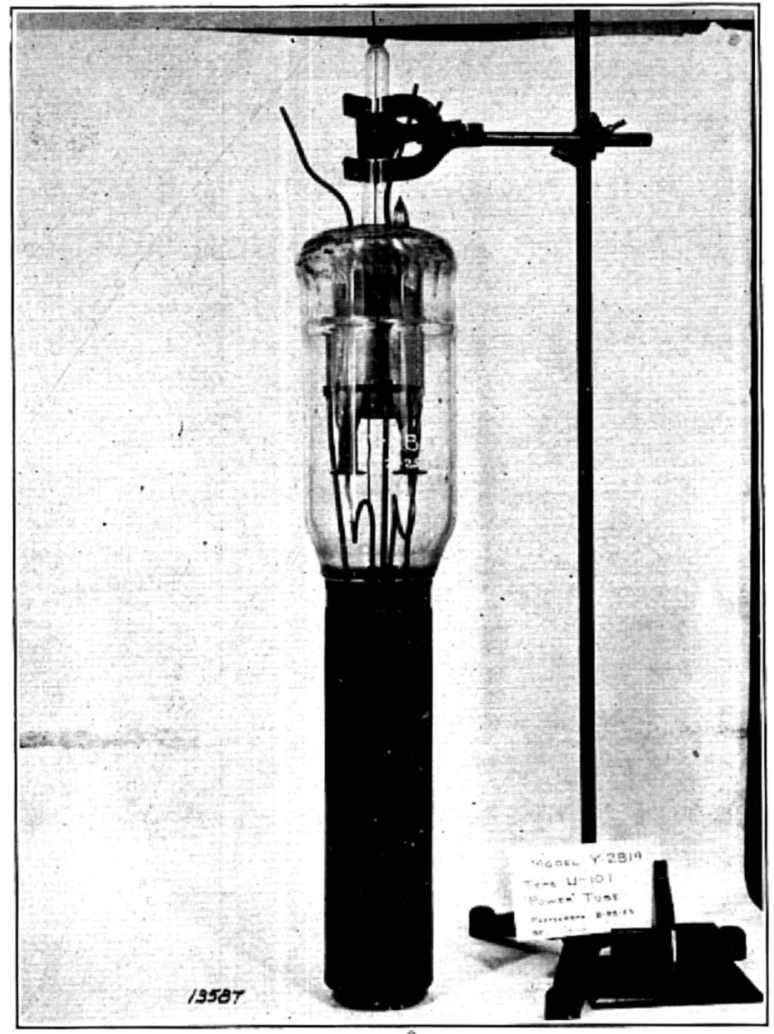

FIr. 10

away with the leaks that were troublesome in the older tubes and the manufacture of the tube can be carried out with certainty.

With this tube as much as $12 \mathrm{k}$. w. have been obtained in an artificial antenna working at 12,000 volts. This power was obtained at a frequency of 600,000 cycles corresponding to 500 meters wave length. The difficulties of obtaining this amount of power at this frequency using a number of smaller tubes in parallel, are obvious to anyone who is acquainted with the problem. On a D. C. test the anode was found to be capable of dissipating $26 \mathrm{k}$. w. when cooled with water. 
The success which had attended the development of a tube of this high power capacity indicated the possibility of constructing still larger tubes and it was decided to proceed with the development of a tube capable of delivering at least $100 \mathrm{k}$. $\mathrm{w}$. into an antenna.

The development proceeded with a few minor alterations along the lines of the smaller tube, nominally rated at $10 \mathrm{k}$.w. and the $100 \mathrm{k}$.w.

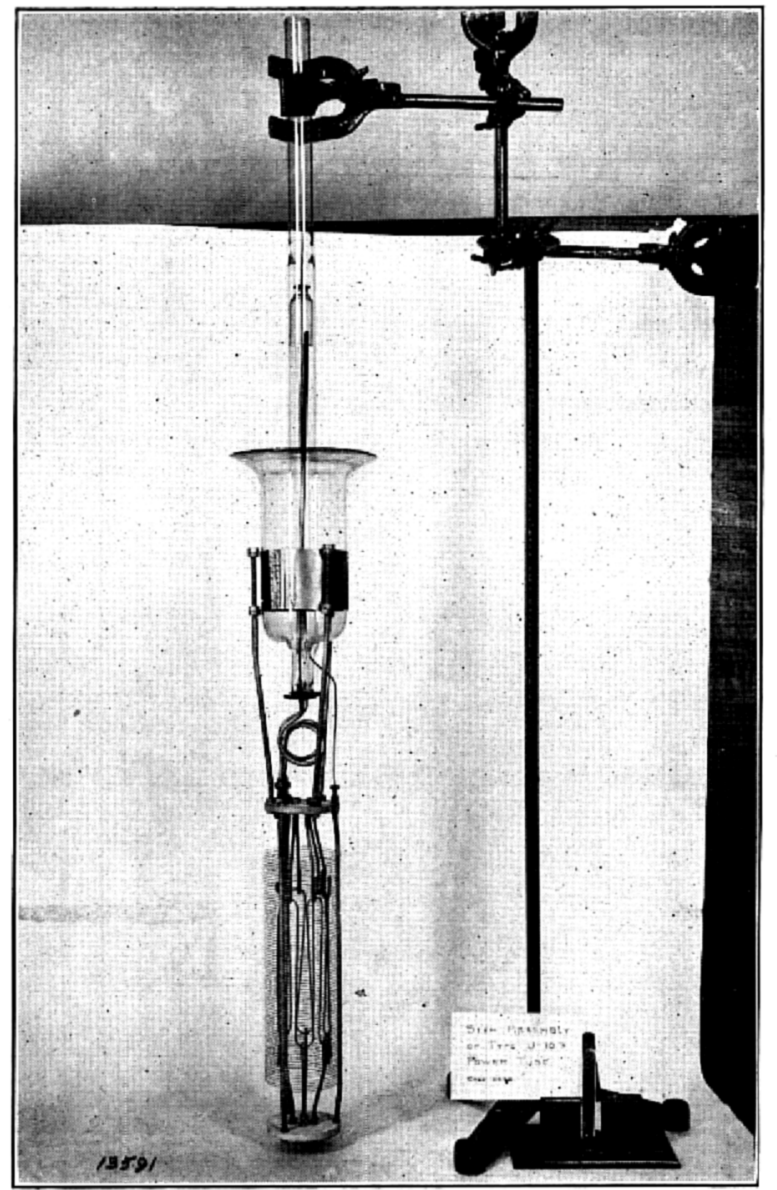

FIG. 11

tube as now developed is shown in Figs. 10 and 11. The anode which is made of a piece of seamless copper tubing closed by a copper disc welded into the end, is $14^{\prime \prime}$ long and $3.5^{\prime \prime}$ in diameter. The filament is of tungsten and is $.06 \mathrm{O}^{\prime \prime}$ in diameter and $63.5^{\prime \prime}$ long. The current required to heat it is 91 amperes and the power consumed in it $6 \mathrm{k}$. w. 
The filament leads are of copper rod one eighth of an inch in diameter and are sealed through $1^{\prime \prime}$ copper disc seals. The grid is of molybdenum and is wound around three molybdenum supports.

The handling of the parts of this tube during manufacture presents a task of no mean magnitude and numerous fixtures have been devised to assist in the glass working. It has been found necessary for instance to suspend the anode in gimbals during the making of the tube scal owing to its great weight, and special devices have been made to hold the filament grid assembly in place while it is being sealed in, otherwise the strains produced by its weight cause cracking of the seal.

The significance of this development in the radio art cannot be overestimated. It makes available tubes in units so large that only a very few would be necessary to operate even the largest radio stations now extant, with all the attendant flexibility of operation which accompanies the use of the vacuum tube.

From the standpoint of wireless telephony the development of these high power tubes gives us the possibility of using very much greater amounts of power than have ever been readily available before. The filaments in these tubes have been made so large that the electron emission from them will easily take care of the high peak currents accompanying the transmission of modulated power.

The $100 \mathrm{k}$. w. tube by no means represents the largest tube made possible by the present clevelopment. There is no doubt that if the demand should occur for tubes capable of handling much larger amounts of power they could be constructed along these same lines. 